\title{
Single-center experience with pediatric patients on ECMO who received recombinant factor VIla for refractory bleeding
}

Fahad Alsohime $^{1,2}$, Karen Harrington ${ }^{1}$, Suzanne Vobecky ${ }^{1}$, Julie Tremblay ${ }^{1}$, Baruch Toledano ${ }^{1}$

Address for Correspondence:

\section{Fahad Alsohime}

${ }^{1}$ Department of PICU, Sainte-Justine Hospital, Montreal,

QC, Canada

${ }^{2}$ College of Medicine, King Saud University, Riyadh,

Saudi Arabia

Email: dr.fahad.alsohime@gmail.com

http://dx.doi.org/10.5339/amj.2017.swacelso.69

(C) 2017 Alsohime, Harrington, Vobecky, Tremblay, Toledano, licensee HBKU Press. This is an open access article distributed under the terms of the Creative Commons Attribution license CC BY 4.0, which permits unrestricted use, distribution and reproduction in any medium, provided the original work is properly cited.

Cite this article as: Alsohime F, Harrington K, Vobecky S, Tremblay J, Toledano B. Single-center experience with pediatric patients on ECMO who received recombinant factor VIla for refractory bleeding, Qatar Medical Journal, 4th Annual ELSO-SWAC Conference Proceedings 2017:69 http://dx.doi.org/10.5339/qmj.2017. swacelso. 69

\section{Oa ascIEnCE.com}

Introduction: Bleeding is the most frequent complication in patients receiving veno-arterial or veno-venous extracorporeal membrane oxygenation (ECMO). ${ }^{1,2}$ Recombinant activated factor VII ( $\left.r F V I l a\right)$ has been used in these patients with conflicting results. We describe our experience in pediatric patients on ECMO who received rFVIla for refractory bleeding in whom conventional management was not successful. This conventional management to stop the bleeding included adjustment of anticoagulation medications, substitution of clotting factors and platelets, and exclusion of surgical cause of bleeding. ${ }^{3-6}$

Methods: We reviewed the medical records of all the patients who underwent ECMO in our PICU from January 1999 to July 2014 and received rFVIla for refractory bleeding. Clinical characteristics, demographics, type of congenital heart disease, surgical correction, bleeding, thrombotic complications, mortality, and rFVlla dose were documented. Being based on retrospective hospital data, this study is exempt from IRB approval.

Results: A total of 123 patients underwent ECMO in our unit since 1999, and five of them received rFVIla for persistent refractory bleeding during veno-arterial ECMO. All of them had corrective cardiac surgery for congenital defects before installation of ECMO. Bleeding dramatically decreased in four patients (Figure 1), without a major thrombotic event. In one patient, bleeding remained significant and he developed left pulmonary artery thrombosis confirmed by cardiac catheterization, and this patient died. Four patients survived at 48-h after withdrawal from ECMO. 


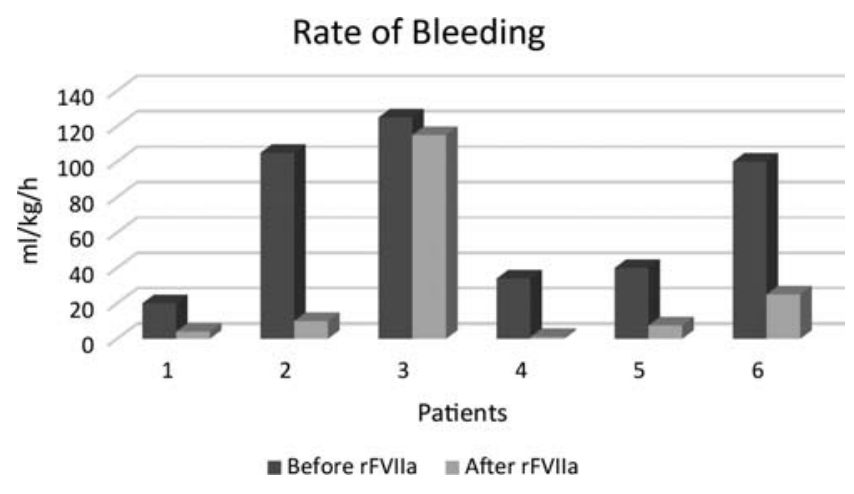

Figure 1. Rate of bleeding in the $3 \mathrm{~h}$ prior to the dose of rFVIla and the $3 \mathrm{~h}$ after the dose of rFVIla.
Conclusions: rFVIla use for refractory bleeding in patients on ECMO was efficacious in four out of five patients in stopping bleeding without major thrombotic events. While the use of rFVIla seems effective, indications for its use, modalities of administration, and precautions to be taken need to be better defined.

Keywords: bleeding, rFVIla, ECMO

\section{REFERENCES}

1. Gaffney AM, Wildhirt SM, Griffin MJ, Annich GM, Radomski MW. Extracorporeal life support. BMJ. 2010;341:c5317.

2. Marasco SF, Lukas G, McDonald M, McMillan J, Ihle B. Review of ECMO (extra corporeal membrane oxygenation) support in critically ill adult patients. Heart Lung Circ. 2008;17(Suppl. 4):S41 - S47.

3. Oliver WC. Anticoagulation and coagulation management for ECMO. Semin Cardiothorac Vasc Anesth. 2009;13(3):154-175.

4. Long MT, Wagner D, Maslach-Hubbard A, Pasko DA, Baldridge P, Annich GM. Safety and efficacy of recombinant activated factor VII for refractory hemorrhage in pediatric patients on extracorporeal membrane oxygenation: A single center review. Perfusion. 2014;29(2):163 - 170.

5. Goudemand J. Recombinant activated factor VII: A new treatment for hemophilia. Transfus Clin Biol. 1998;5(4):260 - 265.

6. Haemostasis Registry Steering Committee. Off-label use of recombinant factor VIla in pediatric patients. Pediatrics. 2012;129(6):e1533-e1540. 